\title{
What are you?
}

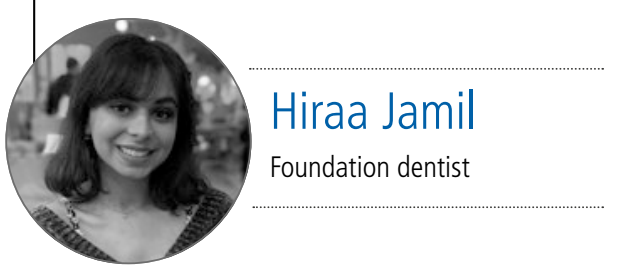

'So Hiraa where are you from?'

'I'm from Manchester'

'No, where are you actually from?'

'Oh well actually, I'm from Rochdale.'

'No I mean what are you?'

In response to those questions, I've recently qualified as a Dentist from Birmingham and I'm from a small town called Rochdale, but what am I? Well what I am is a lot of things; I'm a dentist, I'm a Muslim, I'm a northern lass, I'm British Pakistani, but first and foremost I am a human.

My question is, what does one mean by, 'What are you?' I am constantly questioned about what I am. This is a typical conversation I've had with patients and friends, and one that leaves me feeling alienated.

What people perceive as an innocuous conversation is actually a micro aggressive inquisition where I am having to explain the entirety of my family tree and ethnic background as if I'm an exotic animal being ogled at. You may think 'hang on a minute you're being dramatic', but that in itself is an example of racial gaslighting - invalidating my feelings towards a micro aggressive racial comment. By no means am I implying that the question is asked with a racist intent, but how many times have you been asked 'but where are you actually from?' and how many of you who have been asked this question are white?

This isn't the only instance of racial microaggression I and I'm sure many other BAME people have experienced whilst at dental school or in the world of dentistry.

Unless you've been living under a rock I'm sure you will have heard news about the Black Lives Matter (BLM) movement and the inequalities and systematic oppression faced by members of the BAME community, including the higher rate of infection and death due to COVID-19. According to a report by Advance HE, BAME students made up $37.6 \%$ of students studying medicine or dentistry $^{1}$ and the BDA reports that $28 \%$ of the dental workforce are made up of BAME workers. ${ }^{2} 2020$ was supposed to usher in an era of equality and tolerance, but the current attitude towards minority groups is still very much similar to the attitudes of people during the 1920's. While BAME communities are no longer denied their basic human rights, the systematic racism that underpins society still very much remains the same 100 years later and this has trickled down into our healthcare system and our NHS but in a more insidious form - covert racism and racial inequality.

Those of you who claim racism isn't rife in professional institutions or careers like dentistry and Medicine could not be more wrong. It is a rabbit hole that I have been forced to venture where I have been called a 'Paki' or told to go back to my own country. The further I venture down the rabbit hole, the more occult nuances of racism I encounter.

'This isn't an issue unique
to dentistry, these kinds of
experiences are felt nationally
by members of many
professions. When these
incidents are reported they
tend to yield no consequences'

A frustration of mine is when people place their arms by mine and say 'look I'm almost the same colour as you' or 'I wish I was as tanned as you', I could write a whole thesis on why this is wrong but it would fall upon deaf ears., there's something almost nauseating about people looking at the colour of my skin as if it was fashionable forgetting the struggles that 'my people' have faced because of it. I've been told that I'm not a typical Asian, that I am whitewashed and I've been called a coconut. At first I agreed with these statements, but the more I thought about it the more I began to understand the subtle negative connotations of these - that although my skin may be brown I act as if I'm ashamed of my culture and roots. I've been degraded into a racial fetish by a medical student who wanted to get my 'Punjabi juices' on their fingers; the most hurtful part was being the punchline of a demeaning joke told by my friends which hurt me deeply then and still does.

My patients have expressed on multiple occasions their shock at my noticeably northern accent 'I didn't expect you to sound so British you sound so articulate considering...' considering what? The colour of my skin, the 'exoticness' of my name? My patient's often ask about whether I'll have an arranged marriage and are shocked to discover that I am a Muslim - 'so why don't you wear a headscarf' or 'I'm surprised your parents gave you so much freedom to move away from home, I thought your kind were oppressed?

It's not just limited to patients, I've heard clinical staff liken the messy state of our phantom head suite to the aftermath of a Syrian bomb site and friends of mine have expressed their concern about staff showing a marked indifference towards them compared to their white counterparts. I have overheard dental students mock the accents of Asian and Black guest lecturers, the same students complaining that it annoys them when the 'brown boys speak Indian'. Others have joked that my name and the name of fellow BAME students are too ethnic for them to pronounce or remember.

This isn't an issue unique to dentistry, these kinds of experiences are felt nationally by members of many professions. When these incidents are reported they tend to yield no consequences instead people are told to not make it a 'race thing.' This racial gaslighting not only damages our mental health but also further invalidates the feelings and experiences we feel as the BAME community.

Until we can do better, I - and many, many others - will continue to ponder what the world is like on the other side of the looking glass. •

\section{References}

1. Advance HE, 2019. Equality In Higher Education: Students Statistical Report 2019.

2. British Dental Association. Live Updates: Coronavirus And Dentistry. Available at: https://bda. org/advice/Coronavirus/Pages/latest-updates.aspx (Accessed 6 June 2020) 